\title{
¿Existe un deber del deudor de conocer e informar su situación de insolvencia al tiempo de contratar?
}

\author{
Juan Luis Goldenberg Serrano*
}

\begin{abstract}
RESUMEN
En este trabajo nos preguntamos acerca de la posición que debe tomar el deudor al tiempo de la contratación en lo que se refiere a la ponderación de su propia solvencia, y, en el caso de concluir la existencia de una situación de riesgo para el acreedor, si adicionalmente tiene el deber de alertarlo respecto de ella. Nuestra respuesta a ambas preguntas es negativa, debiendo propiciarse una lectura que active la autoprotección del acreedor, alli donde el ordenamiento escasamente concede herramientas que le resulten útiles para evitar, si no las ha previsto o negociado, la pérdida del crédito.
\end{abstract}

Insolvencia - protección del crédito - deberes de información - acción pauliana

\section{Is there a duty of the debtor to know and inform its insolvency at the time of contracting?}

\begin{abstract}
In this paper we question the position that a debtor shall take at the time of contracting with regards to the valuation of its own solvency and, further, if he must alert his creditor in case be concludes that he is in a risky position. Our answer to both questions is negative. A proper understanding of the law must aim for the creditor's self-protection, where the legal system will scarcely grant him of any useful tool to avoid the loss of the credit, if such measures have not been foreseen and negotiated.
\end{abstract}

Insolvency - creditor protection - information duties - actio pauliana

* Licenciado en Derecho, Pontificia Universidad Católica de Chile. Doctor en Derecho, Universidad de Salamanca, España. Profesor de Derecho Comercial, Pontificia Universidad Católica de Chile. Correo electrónico: jgoldenb@uc.cl

Este trabajo se enmarca dentro del proyecto Fondecyt Regular 1180329.

Artículo recibido el 16 de noviembre de 2018 y aceptado para su publicación en este número el 1 de agosto de 2019. 


\section{INTRODUCCIÓN}

$\mathrm{P}$ or medio de este artículo nos interesa indagar concerniente a la existencia de un deber implícito de todo deudor de conocer y declarar su (in)solvencia al tiempo de la contratación. Esta formulación buscaría establecer una protección especial a favor del acreedor, quien, conociendo una situación de impotencia patrimonial de la contraparte, podría decidir no contratar si los resultados pudiesen serle perjudiciales: primero, si se atiende a que la insolvencia actual del sujeto puede implicar el desvanecimiento del crédito, y, en consecuencia, su insatisfacción ${ }^{1}$; y, segundo, porque el conocimiento del mal estado de los negocios de la contraparte podría resguardarlo del riesgo de revocación del contrato en el marco de la acción pauliana (artículo 2468 CC) o de las acciones revocatorias concursales (Capítulo VI de la Ley No 20.720, o "LRLAEP”), sea mediante la decisión de no celebrar el contrato, sea tomando las precauciones para que este no acarree perjuicio a los acreedores.

El establecimiento de un deber como el señalado no aparece explicitado en la codificación civil, siendo nuestra hipótesis que este simplemente no existe, o, al menos, que su consagración no produce una tutela eficaz para el acreedor. Lo anterior supone advertir, a modo de hipótesis secundaria, que el riesgo de insolvencia actual pesa sobre el acreedor, al tiempo en que solo de modo muy excepcional el ordenamiento dispone de medidas correctoras, siempre y cuando pueda observar la existencia de un tercero a quien pueda dirigirse para la satisfacción del crédito. En este sentido, y dejando a salvo estos supuestos, será el acreedor quien deberá informarse y ponderar la situación patrimonial de aquel con quien contrata, porque a fin de cuentas es su crédito el que se encuentra en riesgo.

El plan por seguir es el siguiente: primero, debemos contextualizar la pregunta en los argumentos que podrían soportar su afirmación, como son aquellos que parten desde la lógica protectora del derecho de crédito y los que se han utilizado para sustentar deberes de información relativos a la solvencia del deudor, construidos a partir de la buena fe (II). Luego se revisarán críticamente dichos argumentos, tanto desde la calificación de la real eficacia de las tutelas que el ordenamiento podría ofrecer con motivo de la falta de información otorgada al acreedor (nulidad, indemnización y adecuación del contrato), como desde la necesaria recalificación del elemento subjetivo de la acción pauliana. A partir de lo anterior, favoreciendo una reordenación del punto desde la perspectiva de la activación de un estándar de autoprotección (III). Todo ello, para terminar con las conclusiones de rigor.

${ }^{1}$ Como integrante del riesgo de inejecución, o, mejor dicho, de los eventuales perjuicios derivados de la misma, el riesgo de insolvencia permite dar cuenta de las consecuencias que resultarán para el acreedor del hecho de que el patrimonio del deudor no sea apto para el cumplimiento de sus obligaciones. Vid. Paraiso, 2011, p. 53. 


\section{LA BUENA FE COMO SOPORTE DE UN DEBER ATÍPICO DE INFORMACIÓN PRECONTRACTUAL RELATIVO A LA SITUACIÓN PATRIMONIAL DEL DEUDOR}

Debemos empezar reiterando que nuestro ordenamiento civil no expresa un deber del deudor de conocer y de informar acerca de la situación de insolvencia previo a la contratación, especialmente si se atiende el escaso interés que posee nuestro Código respecto de la órbita precontractual. Así, las únicas referencias que encontramos de supuestos de "insolvencia actual", esto es, la existente al tiempo de la contratación, se sitúan en sede de novación por cambio de deudor (artículo 1637 CC) y de cesión de créditos (artículo 1907 CC). No obstante, una lectura atenta a dichas disposiciones indica que ellas solo pretenden identificar a un tercero que pueda resultar obligado en virtud de la mentada insolvencia (el delegante o el cedente, según el caso), pero nada indican del comportamiento esperado por parte del propio deudor. Cuestión llamativa si se supone que es este quien se encontraría en mejor posición para conocer de su propia situación patrimonial y declararla al acreedor ${ }^{2}$.

No encontrando una disposición que expresamente atienda ello, debemos preguntarnos si es posible identificar estos deberes como resultado de la aplicación del principio de buena fe (artículo 1546 CC). Si bien estos se desplegarían en las tratativas preliminares, su impacto se provocaría en virtud de la lesión del derecho del crédito que resulta de la imposibilidad, o, al menos, de la dificultad de pago que proviene de una insolvencia existente al tiempo de contratar. Así lo concluye, por ejemplo, López Santamaría, quien señala que " $[1]$ a información de buena fe exige, por ejemplo, respecto a los sujetos, que no se incurra en inexactitudes sobre la solvencia de los negociadores", incardinando el discurso en la idea de que los contratantes deben presentar las cosas conforme con la realidad, evitando informaciones falsas o inexactas, o, incluso, la reticencia, en la medida en la que ello puede impactar en los términos del contrato ${ }^{3}$.

Ahora bien, para comprender las raíces de esta formulación, debemos revisar la construcción del crédito (a plazo) a partid de la confianza en las fuerzas patrimoniales del deudor; de la configuración de un deber de informarse de la propia situación patrimonial, construido desde la idea de un comportamiento diligente, y un deber de información precontractual basado en estándares de cooperación orientados a la satisfacción de los intereses del acreedor. A estos aspectos nos dedicaremos a continuación.

\footnotetext{
${ }^{2}$ El punto no parece advertido por el ordenamiento, no solo en las reglas antes mencionadas, sino en todas las normas civiles que se refieren a la situación de insolvencia del deudor. Así, la búsqueda de elementos que justifiquen la extensión de responsabilidad a terceros, también se encuentra en la estructura de las garantías personales, como en el caso de los codeudores solidarios (art. 1522 CC) o de los cofiadores (art. 2367 CC).

${ }^{3}$ López, 2010, p. 328.
} 


\section{La lógica sistemática: la confianza en la solvencia del deudor como soporte del crédito en el modelo del Código Civil}

Toda norma jurídica es reflejo de sus tiempos. El Código Civil responde al movimiento iusfilosófico predominante en la época, la Escuela del Derecho Natural ${ }^{4}$, pero también a un planteamiento económico, en el que el liberalismo imperaba como una forma de promoción del comercio y de la industria. Como resume Ripert, la Revolución Francesa vio en la libertad de producir y de comerciar la mejor manera de asegurar a los hombres la satisfacción de sus necesidades ${ }^{5}$. Si bien lo anterior es advertible desde múltiples variables, nos interesa enfocarnos en la dinámica del crédito, y, en especial, en la tutela que el ordenamiento civil prodiga al acreedor en la eventualidad de su incumplimiento por razones de insolvencia.

Al tiempo del diseño de los contratos, utilizando como paradigma a la compraventa, parece establecerse un marco normal de inmediatez entre la entrega de la cosa y el pago del precio. Pero ello debe contrastarse con una dinámica social que, incluso en el siglo XIX, empezó a requerir del plazo para el cumplimiento de la finalidad de desarrollo antes indicada. Como señala Veniamin, la idea del intercambio inmediato, bajo fórmulas de permuta o de venta al contado, no responde a las necesidades de una sociedad diferenciada, sino que se establece más próxima a fórmulas primitivas de la vida en común. En ellas, las operaciones económicas se encontraban limitadas al tiempo presente, mientras que, en una economía en desarrollo, se observan desde la perspectiva del devenir futuro y, conforme con ello, puede apreciarse su cariz de incertidumbre ${ }^{6}$. Así, el aplazamiento de las obligaciones, especialmente aquellas de carácter dinerario, se verifica bajo la idea del "crédito", más allá de la nomenclatura típica que lo hace sinónimo al derecho personal (art. $578 \mathrm{CC})^{7}$.

En este escenario, el favorecimiento del crédito supone su fundamentación desde la noción de la confianza del acreedor en su pago ${ }^{8}$. Dicha confianza se justifica en términos de la solvencia del deudor, esto es, la fortaleza de su patrimonio para permitir la solución de la deuda. Conforme con ella, se articulan mecanismos que hunden sus raíces en la responsabilidad patrimonial en la que reposan los diversos elementos del cobro de las obligaciones dinerarias. Como señala Díez-Picazo, los ordenamientos consagran facultades a favor de los acreedores "para la conservación de la solvencia del deudor, toda vez que la solvencia constituye el soporte económico de la efectividad del crédito" porque, en definitiva, "la verdadera y auténtica seguridad de los acreedores está en la capacidad económica de su deudor de hacer frente a sus obligaciones" ${ }^{\circ}$.

\footnotetext{
${ }^{4}$ Ripert, 1936, p. 91; LÉvy y Castaldo, 2002, p. 793.

5 RIPERT, 1936, p. 127.

${ }^{6}$ LeSTAPIS, 1941, p. 170, al insistir que hay un alea necesario en el crédito, no pudiendo ser erradicado, por mucho que legislativamente se intente.

7 GUZMÁN, 2014.

${ }^{8}$ Lestapis, 1941, p. 168.

${ }^{9}$ Díez-Picazo, 2008, pp. 128-129.

${ }^{10}$ Díez-Picazo, 2008, p. 152.
} 
Esta confianza se encuentra sujeta a reglas institucionales, y no a meros sentimientos del acreedor, de modo que el sistema se ofrece desde la idea de que la contratación constituye un mecanismo de cohesión social ${ }^{11}$, en la que todas las partes contribuyen a la correcta circulación de la riqueza y al progreso de la colectividad. Si se sitúa el crédito en el centro de las relaciones económicas, se puede comprender que el ordenamiento pondrá atención en la protección del acreedor ${ }^{12}$, especialmente en situaciones en que el cumplimiento efectivo de la obligación sea puesta en riesgo. Al contrario, la posición del deudor queda desmerecida en la codificación, por medio de tutelas más bien débiles al contrastarlas con las múltiples herramientas concedidas al acreedor para la recuperación de la deuda, en particular, ante supuestos de insolvencia ${ }^{13}$. Así visto, el ideal codificador queda sustentado desde una perspectiva idealista, en la que no se aprecia tal tutela desde la realidad efectiva del crédito, sino desde una ilusión de igualdad y falta de dependencia económica ${ }^{14}$. La visión estaba centrada en el ámbito mercantil, donde ya en nuestras tierras se había observado la necesidad de contar con una normativa más precisa que asegurase la posición de los acreedores, especialmente en el marco de las leyes de prelación de crédito de 1845 y $1854^{15}$, y, con algún retardo, en la configuración de un drástico sistema concursal en el que se invocaban razones de interés público para el correcto funcionamiento económico ${ }^{16}$. Por tanto, el modelo económico del Código se centraba en los préstamos concedidos a aquellos que contasen con riqueza de respaldo (especialmente, bienes raíces) ${ }^{17}$ o en los créditos para fines comerciales ${ }^{18}$, que terminaban cubiertos con una amenaza pública que destinaba al comerciante insolvente, salvo excepciones, a las más duras sanciones corporales y patrimoniales por medio de la figura de la quiebra.

Entonces, siendo la confianza el punto central en esta construcción, un primer acercamiento podría advertir que ella también necesitaría del intercambio informativo entre acreedor y deudor respecto de la situación patrimonial de este último. Y, con ello, podría sostenerse que el deudor vulneraría esa confianza al tiempo de omitir cualquier

11 WARNOTTE, 1927 , p. 108.

${ }^{12}$ Lestapis, 1941, p. 163. Hauriou, 1910, p. 191, subraya que estos propósitos, que requieren de la idea del crédito, consideran el avance efectuado, el riesgo asumido y el valor sacrificado, todo sobre la base del buen funcionamiento de la mecánica del intercambio. Ello necesita que el crédito sea reembolsado, que el perjuicio de la demora sea reparado y que sus sacrificios encuentren una contrapartida, si se quiere que continúe la colaboración de todos en vistas a la satisfacción de las necesidades humanas, porque ella reposa en la confianza y en la buena voluntad universal.

13 Goldenberg, 2017.

14 WarnotTe, 1929, p. 107. De las fuerzas que alertaron acerca de la construcción social de este modelo, y su influencia en la noción misma de contrato, vid. SAVATIER, 1964, pp. 48-65.

${ }^{15}$ BARRIENTOS, 2015, p. 74.

${ }^{16}$ Goldenberg, 2015, pp. 21-31.

${ }^{17}$ Así se desprende del Mensaje del Código Civil, en el que puede leerse, luego de dar cuenta de la formulación de la propiedad registral de los inmuebles, lo siguiente: "Son patentes los beneficios que se deberían a este orden de cosas (...) la hipoteca cimentada sobre base sólida; el crédito territorial vigorizado y susceptible de movilizarse".

${ }^{18}$ De la incidencia comercial en la configuración del contrato, vid. HAURIOU, 1910, p. 190. 
indicación acerca de una situación patrimonial delicada, o, incluso, incurrir en ardides para la obtención del crédito a pesar de su insolvencia. Más allá de las consecuencias penales que podría implicar tal vulneración ${ }^{19}$, nos interesa revisar la forma en la que, desde el punto de vista civil, se podría consagrar un deber de información y los efectos de su infracción, como supuestos medios de prevención que favorecerían la posición del acreedor.

\section{Las fases del deber de información respecto de la (in)solvencia del deudor}

a. El deber de informarse de la propia solvencia

En primer término, el deber de informarse concerniente a la propia solvencia reposaría en la identificación de un comportamiento leal que no solo involucraría el deber atípico de información al que haremos referencia más adelante, sino que también se configura en una etapa previa en la que el deudor debe desplegar conductas activas para conocer dicho estado. Lo anterior, porque solo puede informarse aquello que es conocido. En los casos en que exista un desconocimiento del contenido de aquello que se debe informar, solo es posible provocar un efecto jurídico en los casos en los que pueda sostenerse que el ordenamiento ha configurado un deber previo de informarse, y, sobre esta base, establecer un estándar de diligencia en el que podamos advertir si, en atención a las circunstancias del caso y a las capacidades técnicas del sujeto, es posible imputar los resultados lesivos de la ausencia de comunicación a quien efectivamente pudo conocer una determinada circunstancia. Ejemplo paradigmático de lo anterior se encuentra en el tratamiento de los vicios redhibitorios (artículo $1861 \mathrm{CC})^{20}$.

Como soporte normativo de esta formulación en el ámbito que nos interesa podrá tenerse a la vista la configuración del elemento subjetivo de la acción pauliana (artículo 2468 CC), en lo relativo al conocimiento del mal estado de los negocios por parte del deudor al tiempo de la celebración del negocio jurídico cuestionado. La pregunta se formularía en torno a si es posible interpretar el cumplimiento de tal requisito no solo desde la alternativa del conocimiento efectivo, sino verlo asimismo satisfecho en caso de que el deudor no hubiese llevado a cabo una indagación diligente respecto de su solvencia al tiempo de la contratación, debiendo hacerlo. Lo anterior depende de la comprensión que demos al mentado elemento subjetivo en nuestro ordenamiento, en la medida que tal conclusión solo sería admisible en tanto esta se enfoque desde la noción del conocimiento, real o hipotético, del perjuicio que el acto puede causar a los acreedores.

Como muestra de este planteamiento, mediante sentencia de 10 de noviembre de 2016, la Corte Suprema resolvió lo siguiente: "[l]a conducta del deudor se considera fraudulenta cuando era o debía haber sido consciente del perjuicio que el acto podía causar en sus acreedores, pues entiende que es un deber del deudor, conforme a la buena

\footnotetext{
${ }^{19}$ Por ejemplo, art. 160 de la Ley General de Bancos (DFL N 3 de 1997).

${ }^{20}$ De la Maza, 2010a, pp. 82 y 83.
} 
fe, conocer la situación de su patrimonio y conocer de su solvencia” ${ }^{21}$. Así, siguiendo un criterio bastante asentado en nuestra jurisprudencia (y en parte de la doctrina nacional ${ }^{22}$, se insiste en la calificación del elemento subjetivo como "fraude", situando en este el punto focal de la acción. Pero aun cuando el artículo 2468 CC advierte que tal elemento reposa en el mero conocimiento del mal estado de los negocios, la sentencia en comento refiere a una conciencia de perjuicio que deslinda, en el ámbito superior, con el dolo, $y$, en el inferior, con un nivel de culpa con representación que no queda precisado en su texto. De este modo, la sentencia reseñada añade que "en el fraude de acreedores hay que entender por mala fe/fraude, el mero conocimiento o la ignorancia culpable -el haber conocido o haber podido diligentemente conocer-, en el momento de ejecutar el acto de enajenación, del perjuicio causado al acreedor con el específico acto de enajenación, esto es, que dicho acto causaba o agravaba la insolvencia del deudor, no siendo necesario (aunque de darse también conlleva mala fe/fraude) la intención de dañar al acreedor". Con ello, elevando el estándar previsto por el legislador, la sentencia ha pretendido un acercamiento a la sciencia damni ${ }^{23}$. En consecuencia, no se exigiría un animus nocendi (esto es, la intención directa de perjudicar) ${ }^{24}$, bastando la representación del resultado perjudicial y la aceptación del mismo al tiempo de realizar el acto impugnado ${ }^{25}$.

La comprensión del denominado "fraude pauliano" como "el conocimiento por el deudor de que el acto que celebra provoca o agrava su insolvencia" ${ }^{26}$, no es desconocida en el Derecho comparado, de donde Vargas toma los fundamentos de su posición ${ }^{27}$. Así, por ejemplo, en el derecho francés, la lacónica expresión de la regla en el artículo 1167

${ }^{21}$ Corte Suprema, 10.11.2016, rol 17.517-2016.

22 Román, 2011, p. 696; Abeliuk, 2014, p. 912.

23 O conciencia del daño que se causa a los acreedores, en los términos expuestos por FuEyo, 1958, p. 381. Al efecto, agrega (p. 382), “[E]n este fraude está incluido, naturalmente, la intención de dañar a los acreedores. Pero no será lo más corriente encontrar esa intención específica. Basta lo que es más frecuente: basta la conciencia e estar causando un daño, pudiendo consistir la intención misma en un beneficio propio o en favor de un tercero, que puede ser incluso otro acreedor".

${ }^{24}$ La configuración del elemento subjetivo por medio de un criterio más intenso, como el animus nocendi, también ha sido sostenido por nuestra jurisprudencia cuando elabora la idea del fraude pauliano bajo la idea del "ánimo de perjudicar a los acreedores”. En este sentido, Corte Suprema, 24.5.2016, rol 22.750-2015; Corte Suprema, 31.3.2015, rol 30.917-2014; Corte de Apelaciones de Santiago, 2.1.2015, rol 9392-2014; Corte de Apelaciones de Concepción, 31.3.2017, rol 1727-2016. De modo similar, encontramos referencias a la conducta maliciosa del deudor al ejecutar los actos o al empobrecimiento intencional, como, por ejemplo, en Corte Suprema, 19.10.2017, rol 19.111-2017. En el ámbito doctrinal, la fundamentación en el dolo, como animus nocendi, encontramos a FUeYo, 1958, p. 380; Troncoso, 2011, p. 231, y, parcialmente (como una especie de dolo o de mala fe), en Abeliuk, 2014, p. 912.

25 Ello, aunque se haya sostenido que la comprobación de la mala fe "requiere una manifestación externa y que puede consistir en conductas directas o en circunstancias en las que el otorgante y adquirente estén involucrados de modo relevante" (Corte de Apelaciones de Concepción, 31.3.2017, rol 1727-2016).

${ }^{26}$ VARGAS, 1949, p. 112

27 VARGAS, 1949, pp. 113-114, la que se resume en la idea de que el conocimiento de la insolvencia constituye una prueba imperfecta del animus nocendi, que conformaría el núcleo del fraude pauliano. De tal suerte, siguiendo a Planiol y RIPERT, concluye que "la conciencia de estar causando un perjuicio importa la aceptación del mismo y, en cierto modo, la voluntad de causarlo". 
del Code original dio lugar a mayores dudas ${ }^{28}$, situándose el problema en la significación del fraude. Soutonie-Laguionie advertía las vacilaciones jurisprudenciales para definir la intención fraudulenta al deudor, la que, en todo caso, no era puesta en duda en el contexto francés; el problema estaba en su sentido, situándose entre la intención de perjudicar al acreedor o la mera conciencia del perjuicio causado ${ }^{29}$, incluso distinguiendo si el acto atacado tiene un carácter oneroso o gratuito ${ }^{30}$. Si bien la tendencia parecía encaminarse a la segunda opción, el cuestionamiento no solo se refería a los mecanismos probatorios para reconocer tal conciencia, acaso lograda por medio de presunciones o deberes implícitos de diligencia, sino porque se requeriría constatar previamente el perjuicio causado por el acto, lo que siendo posterior en el tiempo, envolvería un ejercicio de proyección. De este modo, se podría argumentar que, en tal ejercicio, el deudor debería desplegar diligentemente acciones positivas para evitar el perjuicio que, en razón de la creación o agravación de la insolvencia, podría ocasionarse a sus acreedores.

Por otra parte, el artículo 2901 del Codice Civile italiano, expresando los requisitos de procedencia de la acción revocatoria, dispone que el deudor debe conocer el perjuicio que el acto implica para los acreedores (sciencia damni) o, tratándose de un acto anterior al nacimiento del crédito, fuese dolosamente preordenado con el fin de perjudicar su satisfacción (animus nocendi) ${ }^{31}$. Dejando de lado esta última posibilidad, que será aquella que implica mayor dificultad probatoria, la primera impone una valoración de culpabilidad, similar a la que podría deducirse de la regla francesa, en el sentido que el deudor no ha tenido la diligencia debida para la proyección de los resultados del acto realizado en la posibilidad de satisfacción de sus acreedores, suponiendo el conocimiento de su estado de insolvencia actual, o la que resultaría del perfeccionamiento del acto cuestionado ${ }^{32}$. Como tal, se trata de un requisito envuelto en un juicio de previsibilidad del daño, pero no se satisface en sí mismo, porque se añade la necesidad de comprobar el conocimiento del perjuicio previsto ${ }^{33}$. Y, si este elemento no es factible de conocer, se ha agregado, por equiparación de la culpa grave al dolo, la ignorancia inexcusable de la valoración de

${ }^{28}$ Marcadé, 1850 , p. 406, sostiene que los redactores se contentaron con consagrar el principio de la acción pauliana, sin efectuar desarrollo alguno respeto de su naturaleza y a sus efectos; a lo que ZACHARIÆ, 1842, p. 330, agregaba la necesidad de completar las lagunas dejadas por el Code mediante el recurso a sus antecedentes romanos. Las vacilaciones en la interpretación de la regla francesa dieron curso a su reformulación en el actual artículo 1341-2 (conforme con Ordenanza 2016-131, de 2016), que aclara su naturaleza (como acción de inoponibilidad), disponiendo que solo respecto de los actos a título oneroso es necesaria la comprobación del conocimiento del fraude por parte de terceros contratantes.

29 Sautonie-Laguionie, 2008, p. 320.

30 Sautonie-Laguionie, 2008, p. 321.

${ }^{31}$ En los otros sistemas, nos indica Palumbo, 1935, p. 106, la traslación del concilium fraudis a una especie de fraus praeiudicii, provendría de las conocidas ideas de Baldo (decocto ergo fraudator), que fundaron el trato infamante del derecho de la insolvencia. Vid. GoldenberG, 2015, p. 24.

32 STOLFI, 1932, p. 355. Esta posición es explicada por VARGAS, 1949, p. 113, sosteniendo que "no es siquiera necesario probar el conocimiento por el deudor de su propia insolvencia, sino que basta que tal hecho haya sido previsible. Así, podría revocarse un acto aunque el deudor ignorara por negligencia su estado de insolvencia, siempre que dicho acto dañara a los acreedores".

33 Nicolò, 1953, p. 212. 
tal perjuicio ${ }^{34}$. Con ello, fraude y daño se encuentran en directa relación ${ }^{35}$, igualándose los resultados entre el conocimiento efectivo y la simple posibilidad de conocimiento.

Si esta construcción es posible en nuestro ordenamiento, lo que objetaremos más adelante, podría sostenerse que el deudor siempre debería llevar a cabo el examen de su solvencia al tiempo de la contratación, con el fin de evitar un daño a sus acreedores. Si no lo hiciese, podría configurarse un actuar negligente que ha conducido a la insatisfacción del crédito o, en similar línea de argumentación, no podrían alegar el desconocimiento de la precariedad de su situación patrimonial por ser este inexcusable.

\section{b. El deber de informar la situación de (in)solvencia}

Luego, y pensando que el deudor ya tiene conocimiento del estado de sus negocios, la buena fe impondría un deber especial de comunicación, de manera que el deudor debería alertar al acreedor respecto de su situación patrimonial, sea que se encuentre en insolvencia o muy próximo a ella. El fundamento de lo anterior se encontraría en que esa información resultará necesaria para el cumplimiento de las finalidades del contrato y para la satisfacción de los intereses de las partes sobre la base de una indispensable cooperación ${ }^{36}$. Este deber de cooperación, entendido genéricamente como un "criterio de conducta que se basa en la fidelidad al vínculo contractual y en el empeño en cumplir la legítima expectativa de la otra parte" 37 , en este caso supondría que la alerta de la situación patrimonial es indispensable para que el acreedor pondere de forma adecuada los riesgos a los que se expone si decide contratar. Así, debido a que a partir de tal información podrá colegir la fortaleza patrimonial del deudor ${ }^{38}$, aquel podrá decidir romper las negociaciones preliminares, contando para ello con una razón objetiva -no $\operatorname{arbitraria}^{39}$, ilegítima o abusiva ${ }^{40}$-; o, alternativamente, fijar las condiciones particulares del contrato que le ofrezcan una mayor protección (por ejemplo, mediante la contratación de garantías reales o personales).

Siguiendo el diseño propuesto por De la Maza, el citado deber se configuraría de forma atípica en el sentido que no encuentra un reconocimiento expreso por parte del

${ }^{34}$ NiCOLÒ, 1953, p. 213.

35 Palumbo, 1935, p. 119.

${ }^{36}$ La construcción de la obligación de información, en general, a partir del deber de colaboración existente entre las partes puede observarse en Demogue, 1931, pp. 9 y 10. En nuestro entorno, este deber de cooperación es analizado por SAN MARTín, 2009, pp. 135-196, y retomado en SAN MARTín, 2012, pp. 553-554.

37 SAN MARTín, 2012, p. 553.

38 Como señala SAN MARTín, 2009, p. 139, “cuando hablamos de 'deber de cooperación' nos referimos a un conjunto de deberes secundarios de conducta que la buena fe impone a deudor y acreedor, a fin que la ejecución de la prestación resulte lo más ventajosa posible para ambos", empeñándose "en satisfacer íntegramente el interés de la parte acreedora de la prestación” (p. 141), imponiendo, incluso "deberes de información” (p. 142).

39 Barrientos, 2010, p. 50.

40 Zuloaga, 2006, p. 237. 
ordenamiento y, en consecuencia, solo podrá deducirse de los parámetros generales de la buena fe objetiva ${ }^{41}$. Pero incluso en este caso, si existiese un deber de informar respecto de la situación de insolvencia en la que se encuentra el deudor, ella revestiría particularmente la forma de un "deber de alerta" 42 . Lo anterior implica que dicha comunicación tendrá sentido en la medida en la que exista un verdadero peligro para el acreedor. Sostener lo contrario importaría que, en cada relación contractual, debería acreditarse la situación patrimonial por parte del deudor a efectos de conferir adecuado resguardo a las partes, cuando, en realidad, los fines a satisfacer por medio de un deber de información tenderían a configurar una tutela adecuada a la posibilidad de satisfacción del acreedor. Por ello, el deber de información no se referiría a la solvencia del sujeto, como aspecto positivo, sino a la comunicación de su situación de insolvencia, como elemento negativo, que amerita generar una advertencia.

\section{LAS DEFICIENCIAS DE LA ARGUMENTACIÓN ANTERIOR} Y SU REFORMULACIÓN A PARTIR DE LA AUTOPROTECCIÓN DEL ACREEDOR

\section{La ineficacia de los mecanismos de tutela derivados de la formulación de la infracción de los deberes de información relativos a la (in)solvencia del deudor}

En primer término, es del caso preguntarse si un comportamiento leal de los sujetos supone necesariamente una indagación previa de la propia solvencia al tiempo de la celebración de toda clase de contratos. Al efecto, un punto de partida consiste en determinar qué entendemos por solvencia para estos efectos, lo que supone una empresa de difíciles resultados en atención a todos los desvaríos que ello ha planteado para la doctrina, nacional y extranjera ${ }^{43}, y$, especialmente para la jurisprudencia ${ }^{44}$. Sin perjuicio de lo anterior, y para efectos de no entrar en las profundidades de tal debate, creemos que

${ }^{41}$ De la MaZa, 2010a, pp. 84 ss.

42 Rastros del "deber de alerta" lo encontramos en Demogue, 1931, p. 28. Fabre-Magnan. 2014, p. 381, lo reconoce como el deber de dar cuenta a la contraparte "sobre un aspecto negativo del contrato o de la cosa objeto del contrato. Es principalmente un peligro, un riesgo, que debe ser puesto en advertencia de alguien" (traducción propia). Se le designa también como "obligación de previsión”, "deber de guía” o "deber de advertencia”. En nuestro entorno, se han referido a este deber, entre otros, BARRos y RioseCo, 2015, p. 633, para distinguirlo de la mera información, del consejo y de la recomendación; SAN MARTín, 2012, pp. 547-560, en materia de caso fortuito o fuerza mayor; GoldenBERG, 2018, pp. 27 y 28, para diferenciarlo del deber de asesoramiento. En un trabajo aún no publicado, la profesora Patricia López Díaz se refirió a esta categoría en su ponencia presentada en las XVI Jornadas Nacionales de Derecho Civil, organizadas en octubre del 2018 por la Universidad de Chile en la ciudad de Coquimbo.

43 Alemán, 2010.

${ }^{44}$ Por ejemplo, en Corte Suprema, 10.9.1984, se expresó que la insolvencia estaba dada por la incapacidad para el pago de las deudas, independientemente de que su activo pueda ser superior a su pasivo; criterio que se mantiene en Corte de Apelaciones de Concepción, 8.10.2010, rol 496-2010. Al contrario, en Corte Suprema, 17.8.2011, rol 828-2010, se sostuvo que la insolvencia es "el estado en que se encuentra el patrimonio de una persona cuando el pasivo es superior al activo, de suerte que ella queda imposibilitada 
la articulación de un deber como el propuesto importaría utilizar un concepto funcional de insolvencia, verificando la tutela que realmente se desea conceder al acreedor. En este sentido, este deber se justificaría para evitar el perjuicio que al acreedor le puede significar la pérdida del crédito, y, con ello, sostener que la insolvencia dará cuenta de una situación patrimonial que pone en evidente riesgo la pretensión satisfactoria del acreedor.

Así, al tiempo de provocar un examen del deudor respecto de su situación patrimonial, este solo se encauza en la insolvencia actual, lo que supone un deber de conocer el buen o mal estado de los negocios al momento de contratar. Con ello, el ejercicio no envuelve una proyección del estado futuro del patrimonio, sino la constatación de una circunstancia de hecho que impone su fortaleza o debilidad para dar correcta cobertura a sus obligaciones. No obstante, el deber sí incorporaría un elemento de proyección, que no se conectaría con la situación patrimonial actual, ya cristalizada para efectos del análisis, sino que se desenvolvería en el eventual impacto que tendría en esta la celebración del contrato aún en fase de negociación. Visto de este modo, el planteamiento tan general de esta suerte de deberes desatiende las dificultades que impone este ejercicio. Salvo en los casos en los que una situación de debilidad sea evidente, suponer que todo sujeto está en posición de efectuar un análisis financiero de su propia situación patrimonial puede parecer desmedido, desconociendo incluso el carácter técnico que suele fijarse para ponderar la propia existencia del deber.

Adicionalmente, aun cuando la línea de argumentación presentada en la sección II precedente pueda aparecer seductora, el cuestionamiento se produce en torno a la eficacia de las consecuencias civiles derivadas de la infracción de esta suerte de deberes de información. Lo anterior, no para negar rotundamente su existencia, sino para observar la debilidad de la protección que ellas tendrían para el acreedor ${ }^{45}$. Si, por una parte, su infracción importase un supuesto de reticencia, o, al menos, un error para el acreedor, la solución de la nulidad relativa implicaría la necesaria restitución de aquello que recibió en virtud del contrato, atendiendo a las reglas de las prestaciones mutuas (artículos 1682 y 1687 CC). Si, por la otra, la infracción activase la responsabilidad civil, se obtendría un crédito dinerario para efectos del resarcimiento de los perjuicios. Pero en uno y otro caso, no debemos olvidar que la acción se justificaría en la insolvencia del deudor, y que, para valorar su procedencia, ella debería permanecer al tiempo de su ejercicio. De ello se desprende una escasa posibilidad de recuperación del crédito, especialmente si se tiene a la vista su carácter valista, haciendo inciertas sus posibilidades de cobro en sede concursal ${ }^{46}$. Es por esto por lo que hemos dicho que, ante estos eventos, el código

\footnotetext{
de pagar sus deudas", conservándose dicha noción en Corte Suprema, 23.1.2014, rol 9010-2013, y en Corte Suprema, 7.04.2014, rol 9432-2013.

${ }^{45}$ Con ello se quiere indicar que es conceptualmente posible el ejercicio de la acción de nulidad, por ejemplo, en caso que el acreedor haya consultado acerca de la solvencia del deudor y este haya omitido información relevante o haya mentido en relación con su situación patrimonial. El problema, por tanto, no se refiere a la procedencia de la acción, sino a su utilidad como resguardo efectivo para el acreedor.

${ }^{46}$ En el contexto de la legislación vigente, menores esperanzas podrán advertirse, ahí donde la LRLAEP dispone que, al término de los procedimientos de liquidación, se producirá la extinción de los saldos insolutos (artículo 255 LRLAEP). Del particular, vid. Caballero, 2017.
} 
no estructura soluciones que busquen una respuesta en el patrimonio insolvente, sino, de ser posible, atender a un uno diverso en el que sí pueda optar por la recuperación.

Por su parte, si la solución se enfoca desde la posibilidad de adaptación del contrato, fundado en el favor contractus ${ }^{47}$, supondríamos que una información errada acerca de la situación patrimonial del deudor ha posibilitado una incorrecta organización de los intereses de las partes ${ }^{48}$. No obstante, si es que fuese posible ampliar su aplicación a campos más allá de la lesión enorme ${ }^{49}$, este también resultará ineficaz o impertinente para el caso que tratamos. Si se admitiese una fórmula que pretenda un reequilibrio contractual, en el escenario que proponemos, ella podría conseguirse de dos modos: por medio de un aumento en la tasa de interés en razón del mayor riesgo asumido y erradamente apreciado por el acreedor, caso en que el problema se encontrará en que nuevamente estaremos ante un crédito dinerario (los intereses), que, con motivo de la insolvencia del deudor, correrá similar suerte que el capital adeudado; o, mediante la constitución de garantías reales o personales para asegurar el cumplimiento de la obligación. En el primer caso, el problema se centrará en el riesgo de revocación de las cauciones otorgadas para asegurar obligaciones preexistentes (artículos 287.I.3 y 290.I.3 LRLAEP), mientras, en el segundo, el remedio requeriría de la concurrencia de la voluntad de un tercero garante, lo que en nuestro sistema solo parece exigible al deudor en la medida en la que se tratase de una insolvencia sobreviniente (artículo 2348.2 CC).

\section{La errónea formulación del elemento subjetivo de la acción pauliana}

Al tiempo en que la construcción de un deber de calificación de la propia solvencia descansaría en el comportamiento esperable del deudor, y que este podría deducirse de la comprensión del denominado "fraude pauliano", nuestro interés es explicar, por una parte, que su interpretación tradicional ha supuesto su incardinación en un juicio de imputación que no parece propio de su estructura revocatoria; y, por la otra, destacar que el amplio ámbito de aplicación de la acción pauliana, no solo protectora de los créditos de fuente contractual, es indiciario de que su formulación no puede reposar en criterios de buena fe objetiva que sirvan como elemento integrador del contrato.

\section{a. La culpa como elemento ajeno al sistema revocatorio de la acción pauliana}

Es importante aclarar que el primer problema de la formulación habitual del elemento subjetivo de la acción pauliana es que el texto del artículo 2468 CC no utiliza explícitamente la noción de $\mathrm{fraude}^{50}$, y si acaso fuere posible entender que la mala fe a la que se refieren sus primeros dos numerales pudiesen ser indiciarios de una intención

\footnotetext{
47 LÓPEZ, 2017, pp. 11, 31.

48 Morales Moreno, 2011, p. 413; López, 2017, p. 35.

${ }^{49}$ López, 2017, pp. 23, 110.

${ }^{50}$ Como sí se advierte, en un contexto similar, en los artículos 803, 1568.33 y 1617.4 CC.
} 
fraudulenta, lo cierto es que tal conclusión resulta imprecisa si se observa que el Código tuvo la precaución de evitar el debate, limitando el elemento subjetivo al simple conocimiento del mal estado de $\operatorname{los}_{\text {negocios }}{ }^{51}$. En este extremo, se advierte una toma de posición que no se aprecia en el Code, ni en otros ordenamientos que siguieron su modelo, observando el consilium fraudis desde su connotación clásica, como mera sciencia de l'insolvencia ${ }^{52}$, y no como sciencia damni ni menos como animus nocendi ${ }^{53}$.

Adicionalmente, la construcción objeto de crítica contempla igual falla argumental que la anticipada en el contexto francés, al tratar de la sciencia damni. Aquí el problema es que el perjuicio, entendido como la lesión al derecho de crédito por el compromiso que el acto acarrea en su posibilidad de satisfacción, solo será conocido en un momento posterior a su realización, por lo que la fórmula no debe ser la conciencia del perjuicio causado, sino la conciencia del perjuicio que se puede causar a los acreedores a consecuencia de la celebración del acto impugnado. Y, con ello, el punto se dificulta al fundarse en el expediente de la negligencia, que parece más propio de un modelo de responsabilidad que de un mecanismo de revocación, ya que puede importar una doble objeción escalonada: el deudor sería culpable por haber desestimado el perjuicio que el acto pudo implicar en la posibilidad de cobro de los acreedores, pero también sería culpable por ignorar su situación patrimonial, y, por tanto, la posibilidad de anticipar dicho perjuicio.

Sin embargo, llama la atención la incorporación de la idea de una "ignorancia culpable" o la posibilidad de haber "podido diligentemente" conocer los resultados del acto por parte de quienes concurrieron al mismo, de ser oneroso, o, al menos, del deudor, de ser gratuito ${ }^{54}$. El punto debe ser destacado porque este esboza un nivel de negligencia

${ }^{51}$ En este sentido, SANDOval, 2014, p. 260, afirmando que "no se exige acreditar la mala fe o el dolo, en tanto la intención positiva de perjudicar, como se entiende en el derecho común”. De modo más difuso, PugA, 2014, p. 452, al sostener que la "exigencia de saber de la situación patrimonial del deudor importa una presunción de negligencia o dolo (directo o eventual) de parte de los celebrantes, lo que representa una concepción novedosa de parte de Andrés Bello, un avance hacia su objetivación”; y Román, 2011, p. 697, al afirmar que el elemento subjetivo "reside en el conocimiento del mal estado de los negocios por el mismo deudor. De manera que la expresión "mala fe" se constituye en el núcleo del fraude y siendo un elemento subjetivo, la legislación ha creado una presunción respecto de dicha subjetividad de actuar de mala fe”.

52 Palumbo, 1935, p. 120.

53 No obstante, no se trataba este de un aspecto del todo novedoso en la época de la codificación. Por una parte, la noción de fraude como conocimiento del mal estado de los negocios ya había sido advertida como una forma interpretativa del "fraude" del artículo 1167 del Code (vid. Toullier, 1821, p. 318; MarCadé, 1850, p. 406; Laurent, 1878, p. 507). Por otra, especial atención debe prestarse al Código Sardo (1837, en vigor desde 1838), al que Bello tuvo acceso mediante las Concordancias de Saint Joseph, por cuanto se trata del primer texto que, aunque tomara los antecedentes del Code, distinguió entre actos a título gratuito y a título oneroso (artículo 1258), como en el caso chileno. También debe observarse el Código de Comercio de Cerdeña (1842), no solo porque es el único que hace referencia a la anticresis (artículo 481), como la regla patria, sino también porque establece el requisito subjetivo en el conocimiento de la cesación de pagos del deudor (artículo 482), término que, para estos efectos, debe entenderse como coincidente a la insolvencia y, como tal, presupuesto objetivo del fallimento (artículo 468).

${ }^{54} \mathrm{Al}$ efecto, en este punto es admisible traer a la mente las ideas de Alessandri, al sostener que la acción pauliana pretendería reaccionar ante un acto ilícito que constituye un verdadero delito civil (ALESSANDRI, 1939, p. 207). Lo anterior fue considerado por la Corte de Apelaciones de Concepción, 31.3.2017, 
en la conducta del respectivo sujeto que, en el caso específico, no sopesa de forma adecuada las consecuencias económicas de sus actos. En similar sentido, pero sustentando ahora tal afirmación en la responsabilidad de todo quien contrae una obligación, nuestra Corte Suprema ha señalado que el deudor "también sabrá del efecto que traerá aparejado el debilitamiento en su posición económica por cada acto de disposición que realice" 55 .

Dicha forma de razonar debería alertarnos que el ordenamiento jurídico tendría una expectativa razonable de que las partes se cercioren diligente y adecuadamente de todos los extremos relevantes al tiempo de llevar a cabo un cierto acto de contenido económico, en particular, en lo que pueda referirse al eventual desequilibrio que de él puede resultar. Aquí, y a causa de la estructura de la acción pauliana, el desequilibrio se encuentra reconducido al extremo de la insolvencia (aun cuando la norma no refiere a ella, sino al mal estado de los negocios) ${ }^{56}$, bajo la necesidad de configurar las razones del perjuicio que ameritarían la revocación del acto con el objetivo de proteger el crédito de sus acreedores ${ }^{57}$. De este modo, la reconducción asumiría que, para efectos de prosperar la acción, es necesario que el acto resulte efectivamente perjudicial (eventus damni) y que este daño haya podido ser anticipado por el deudor o por este y el tercero contratante, según sea el caso.

Para estos efectos, de nuevo debemos volver a la idea de que el comportamiento leal supone, en este extremo, conocer la propia situación patrimonial. Sin embargo, afirmamos que la reconducción a la buena fe objetiva como parámetro de conducta resulta insuficiente para la justificación de la acción pauliana. Tal argumentación daría cuenta de una confusión entre la buena fe objetiva y subjetiva, ya que aquella configuraría un deber de conducta que impactaría en la calificación del elemento subjetivo de la acción. Si ello fuese de este modo, la acreditación del conocimiento del mal estado de los negocios, al menos, por parte del deudor, sería innecesaria como presupuesto de la acción, en la medida en que, incluso de haber desconocido tal circunstancia, aquel hubiese infringido un deber de conducta que, impuesto por la buena fe, lo obligaba a declarar aquello que debió haber conocido. En otros términos, si el deudor ejecuta el acto sin conocer el estado de su patrimonio, debiendo conocerlo, de nada importa si ha proyectado o no los resultados del negocio en el ámbito de su responsabilidad patrimonial con sus acreedores, porque esa proyección derivaría del conocimiento que, negligentemente, le ha faltado. Así, bastaría el perjuicio a los acreedores para la revocación del acto ${ }^{58}$.

rol 1727-2016, debe partir de la base que asigna a la acción pauliana la naturaleza de una acción especial de responsabilidad civil.

55 Corte Suprema, 28.5.2015, rol 24.381-2014.

56 Más allá de las dificultades históricas para la definición de la insolvencia, una reconducción que resulta alineada a los fines de la acción paulina es aquella en que se indica que ella pretende la revocación de los actos del deudor que "disminuya su patrimonio en términos tales que la posibilidad del acreedor para satisfacer su acreencia se torne prácticamente imposible” (Corte Suprema, 23.11.2012, rol 3397-2011).

57 En este sentido, Corte Suprema, 30.3.2016, rol 9988-2015.

58 Acerca de este particular, ver Severin y Carvajal, 2016, pp. 807-809. 
Constatado el hecho que parece incuestionado que el ejercicio de la acción pauliana requiere de un elemento subjetivo, cualquiera sea este, el mentado deber conduciría a su negación, y, por tanto, su formulación debe ser desestimada. Como ya indicaba Toullier, "el deudor puede tener deudas que no conoce, y estar insolvente sin saberlo. Los actos que son realizados en todos estos casos no pueden ser considerados como fraudulentos, y no pueden ser atacados, a pesar de que implicar su insolvencia y la pérdida de sus acreedores" 59 .

\section{b. El ámbito de aplicación de la acción pauliana}

Un último punto destacable es que la referencia a la buena fe objetiva en este ámbito podría tener alguna cabida en el contexto de las relaciones contractuales, en las que ella se comporta un elemento de integración del contrato, desplegándose, incluso, en fase precontractual $^{60}$. Pero el ejercicio de la acción pauliana no circunscribe su legitimación activa a los titulares de créditos de origen contractual, siendo indistinta su fuente ${ }^{61}$, solo requiriendo que el nacimiento del crédito tenga una fecha anterior a la del acto impugnado ${ }^{62}$. Lo anterior importa, en lo que nos interesa, que el deber de calificar la propia solvencia al que antes hemos hecho referencia se desplegaría al tiempo en que el individuo (que posee la calidad de deudor de cualquier clase de obligaciones) lleva a cabo cualquier acto, especialmente de disposición, que pudiese conllevar una incidencia negativa en su patrimonio. Se trataría, en consecuencia, más que un deber de lealtad que emana del vínculo contractual, o de la fase preparatoria del mismo, de uno que debería formularse respecto de todo crédito, con independencia de su fuente.

En todo caso, la cuestión se ha analizado desde una perspectiva un tanto diversa, estableciendo un deber que emana de la imperatividad de la regla obligatoria, que provoca la sujeción de su patrimonio al cumplimiento de la obligación. Con ello, se quiere indicar que la responsabilidad patrimonial se observa como una relación en la que, desde su perspectiva pasiva, supone una sujeción, y, desde la activa, una situación subjetiva que permite al acreedor utilizar ciertas medidas, sustantivas y procesales, enfocadas en garantizar la satisfacción de su interés ${ }^{63}$. De este modo, más allá de buscar el contexto de aplicación de la acción, como medio de tutela del crédito ${ }^{64}$, o, como mecanismo auxiliar, se pretendería incardinarla en uno de los elementos en el que, al menos didácticamente, la obligación se divide: la deuda (Schuld) o la responsabilidad (Haftung $)^{65}$. Para estos efectos deberá indicarse que la responsabilidad patrimonial universal no despliega su utilidad solo desde el momento del incumplimiento de la obligación, como soporte de

\footnotetext{
59 Toulllier, 1821, p. 319 (traducción del autor). En similar sentido, Demolombe, 1868, p. 303.

60 BoetsCH, 2011, p. 119.

${ }^{61}$ Ripert, 1949, p. 306.

${ }^{62}$ En este sentido, Corte Suprema, 27.9.2017, rol 30374-2017, al permitir el ejercicio de la acción pauliana respecto de una obligación por responsabilidad extracontractual.

${ }^{63}$ Migliaccio, 2012, p. 19.

${ }^{64}$ Rojas, 2012, p. 3.

${ }^{65}$ Fueyo, 2004, pp. 34-40; Díez-Picazo, 2008, pp. 77-79.
} 
la acción ejecutiva, sino que la solvencia del deudor debe ser tutelada desde su creación ${ }^{66}$. Conforme con ella, el deber del deudor se instala también en la mantención de la estabilidad de dicho patrimonio, configurándose la acción pauliana desde la óptica de un deber de abstención ${ }^{67}$, esto es, de no efectuar actos que terminen por socavar su solvencia, haciendo inoperante la regla de responsabilidad. Por ello, nos indicaba Ripert, el estudio de la acción pauliana se sitúa en el análisis de los deberes del deudor respecto de sus acreedores, de modo que su sola existencia comprueba que la obligación no solo comporta una vinculación de patrimonios, sino que tras ella siempre existen personas, donde el deudor tiene un deber, jurídico y moral, de cumplimiento ${ }^{68}$.

De lo anterior es admisible deducir que el hecho de que la sola creación de la obligación no resta la capacidad de disposición del deudor, no puede significar el desconocimiento del vínculo obligatorio y de la legítima pretensión del acreedor de obtener su cumplimiento. De ello se puede deducir que la finalidad última de la acción pauliana consiste en evitar la realización de actos que puedan hacer imposible o, al menos, comprometan tal ejecución ${ }^{69}$. Pero, a nuestro juicio, esta circunstancia no es resultado de un deber de lealtad, como expresión de la buena fe, sino de la propia construcción del sentido y finalidades del vínculo obligatorio. Por ello, no requiere de una resignificación a partir de la relación contractual, la que ciertamente puede faltar, ni es necesaria su configuración sobre las bases de un deber complementario o secundario que moldee ciertas conductas exigibles que permitan la correcta operatoria del contrato para la satisfacción de los intereses de las partes ${ }^{70}$. Conforme con lo anterior, resultaría indistinta la causa de la obligación o, incluso, la finalidad típica del contrato, ya que cualquier obligación personal da curso a la operatoria del principio de responsabilidad personal y, en consecuencia, la solvencia terminará siendo el resguardo último en que reposa la confianza institucionalizada que pretende el amparo del crédito.

\section{Bases para una reordenación a partir de la idea de la autorresponsabilidad del acreedor}

En lo que respecto del estudio de los deberes precontractuales de información, siempre debe tenerse a la vista la circunstancia de que estos quedan sujetos a los límites que propone, por ejemplo, el principio de autorresponsabilidad ${ }^{71}$. Este significa, como explica De la Maza, que "cada persona debe negociar sus contratos con diligencia, protegiendo sus propios intereses y, por tanto, procurándose la información relevante para tomar la decisión de contratar" 72 . De lo anterior se deduce que, a pesar de los criterios cada vez más expansivos de la buena fe objetiva en la fijación de deberes secundarios

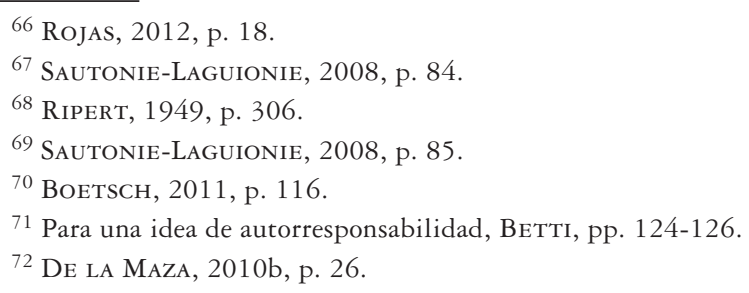


de conducta, siempre quedan espacios en los que podemos construir una carga para proveerse de la información necesaria para la satisfacción de los intereses contractuales. En el caso que nos interesa, la información concerniente a la solvencia del deudor podrá obtenerse de ciertos datos objetivos (por ejemplo, los que se desprenden del nivel de activos, pasivos e ingresos del deudor), o de aquellos que pueden obtenerse a partir de bases generales, como las que proporcionan los bureau de créditos (en Chile, especialmente, DICOM), lo que resulta especialmente cierto de parte de aquellos acreedores que hacen del crédito su negocio habitual ( $v . g r$, bancos, retail, etc.). Particularmente en estos supuestos, parece que la ignorancia respecto de la situación patrimonial del deudor resulta particularmente inexcusable, si se considera que, incluso, algunos de ellos gozan de un acceso más o menos consolidado de información crediticia ${ }^{73}$, o, al menos, ante una situación de incertidumbre, se encuentran en posición para exigir el otorgamiento de garantías que limiten sus riesgos.

Por ello, bien podemos cuestionarnos si es correcto suponer que la ponderación y comunicación de la propia solvencia puede expresarse como deber del deudor, o si hay circunstancias, especialmente donde existe un desequilibrio técnico entre las partes, en que puede parecer más coherente formularlo como una carga informativa del acreedor ${ }^{74}$. Por ejemplo, en el contexto internacional, los contornos del "préstamo responsable" suponen un comportamiento diligente de las entidades financieras, asegurándose que el deudor goza efectivamente de capacidad de pago. De tal suerte, el establecimiento de obligaciones de evaluación de la solvencia del deudor no se plantea ya solo como un modo de asegurar la estabilidad de la banca ${ }^{75}$, sino como núcleo de protección del consumidor ${ }^{76}$, lo que, a nuestro juicio, es igualmente sostenible respecto de cualquier deudor que, sin tener capacidades o conocimientos financieros suficientes, contrate con quien sí las posee: una correcta asignación del riesgo de insolvencia, al menos desde la perspectiva de la eficiencia, debe efectuarse a quien se encuentra en una mejor posición para ponderarlo.

Finalmente, no puede dejar de anotarse que, el contexto general de la insolvencia, la conducta esperable del acreedor parece configurarse preferentemente a partir de esta idea de diligencia, no solo en lo que refiere a la información necesaria, sino a la reacción frente a la posibilidad de pérdida del crédito. De este modo, como explica San Martín precisamente a partir de la idea de la "carga de diligencia”, la inacción frente a la eventual

73 Decretos No 950 (1928) y No 1971 (1945) del Ministerio de Hacienda, artículo 14 de la Ley General de Bancos y Capítulos 18-5 y 20-6 de la Recopilación Actualizada de Normas de la SBIF.

${ }^{74} \mathrm{El}$ punto, sin embargo, puede presentarse de manera inversa si el acreedor es quien se encuentra en una posición técnica desmejorada, como el caso de un inversionista menor que adquiere documentos representativos de deuda de una empresa, confiando en su aparente solvencia.

${ }^{75}$ En Chile, vid. Capítulo B-1 del Compendio de Normas Contables de la Superintendencia de Bancos e Instituciones Financieras.

76 Álvarez Olalla, 2017, p. 732. En el contexto norteamericano, estos deberes se proyectan sobre la base de evitar el comportamiento abusivo del proveedor del crédito (Dodd-Frank Wall Street Reform and Consumer Protection Act). En el ámbito europeo tal obligación aparece establecida en la Directiva 2008/48/ $\mathrm{CE}$, bajo la idea de que "los prestamistas deben tener la responsabilidad de controlar individualmente la solvencia del consumidor". 
insolvencia del deudor termina por disminuir o eliminar la garantía del acreedor, como se refleja en nuestro sistema en la regulación de la excusión en el contrato de fianza (artículos 2356 y 2365 CC) $)^{77}$.

\section{Conclusiones}

La conformación del Derecho de crédito se articula sobre la base de la protección de este a fin de lograr con ello el impulso económico y el desarrollo nacional. De ahí que la lógica del Código Civil plantee un tratamiento favorable a la posición del acreedor, donde el deudor, si es que acaso resulta favorecido, obtiene ventajas para poder aliviar la liberación producto del pago de la deuda. Ahora bien, la intensidad de dicha protección se articula en torno a la necesaria confianza que debe sustentar el sistema, confianza de pago que no se basa en la mera expectativa del acreedor, sino en un diseño institucional que conceda correcta cobertura.

En dicho contexto, y debido a que la insolvencia actual del deudor puede provocar la pérdida del crédito, se ha entendido que, sobre la base de la buena fe, es posible dar cuenta de ciertos niveles de diligencia en el deudor, los que lo llevarían a ponderar su situación patrimonial al tiempo de contratar; como también deberes atípicos de información, en los que aquel debe poner en alerta al acreedor de los riesgos que importaría la generación de un crédito en tal circunstancia. Sin embargo, creemos que ello envuelve una incorrecta lectura del ordenamiento, porque la insolvencia importará la imposibilidad de lograr una correcta protección del deudor en el patrimonio del deudor insolvente, considerando especialmente que el mal estado de sus negocios provocará el desvanecimiento del crédito ante cualquier medio de cobro. Con ello, formulaciones que conllevan la configuración de vicios del consentimiento o de indemnizaciones de perjuicios, si bien podrían ser correctamente articuladas sobre las bases antes señaladas, resultan ineficaces, ante la evidencia de un patrimonio ya deteriorado.

Lo mismo se puede observar desde la lógica de la acción pauliana, toda vez que, a pesar de una línea jurisprudencial que evoca los deberes antes indicados a partir de la buena fe, yerra el punto al sostener un planteamiento equívoco de su requisito subjetivo. Basado en ideas foráneas que no resultan aplicables en nuestro contexto, se omite que, en lugar de una sciencia damni o un animus nocendi, el artículo 2468 CC se satisface con el solo conocimiento del mal estado de los negocios del deudor. Con ello, cabrá sostener que, si dicho extremo no logra ser acreditado, mal podría sostenerse un deber de diligencia del deudor en ponderar su propia situación patrimonial al tiempo de contratar. Si así fuese, el requisito quedaría completamente privado de efectividad.

De todo lo anterior es posible concluir que es el acreedor quien debe desplegar conductas de autoprotección al momento de contratar, al tiempo que el ordenamiento civil solo de manera muy excepcional arbitrará medidas de tutela ante la insolvencia

${ }^{77}$ SAN MARTín, 2012, pp. 329-342. 
actual, ahí donde pueda encontrar a un tercero a quien hacer extensiva la obligación de pago. Fuera de ellos, deberá indagar el estado de los negocios del deudor para efectos de no enfrentarse, tarde o temprano, a la pérdida del crédito.

\section{BiBLIOGRAFÍA}

Abeliuk Manasevich, René, 2014: Las obligaciones, Santiago: Thomson Reuters / Legal Publishing. Alemán Monterreal, Ana, 2010: La insolvencia. Una cuestión de terminología jurídica, Santiago de Compostela: Tórculo Ediciones.

Alessandri Rodríguez, Arturo, 1939: Derecho Civil. Segundo año, Primera parte, Teoría de las Obligaciones, tercera edición corregida, Santiago: Librería y Editorial Zamorano y Caperán.

Álvarez Olalla, Pilar, 2017: "La obligación de evaluar la solvencia y su incumplimiento", en Matilde Cuena (dir.), La prevención del sobreendeudamiento privado. Hacia un préstamo y consumo responsables, Cizur Menor: Thomson Reuters Aranzadi, pp. 725-810.

Barrientos Grandón, Javier, 2015: Historia del Código de Comercio de la República de Chile. Sobre la cultura a través de un libro, Santiago: Producciones Gráficas Limitada.

Barrientos Zamorano, Marcelo, 2010: Daños y deberes en las tratativas preliminares de un contrato, Santiago: Legalpublishing.

Barros Bourie, Enrique, Rioseco López, Andrés, 2015: "Responsabilidad de quien da un mal consejo”, en Álvaro Vidal, Gonzalo Severín y Claudia Mejías (editores), Estudios de Derecho Civil X, Santiago: Thomson Reuters La Ley, pp. 633-651.

BetTi, Emilio, 1930: Teoría general del negocio jurídico (trad. A. Martín), Madrid: Editorial Revista de Derecho Privado.

Boetsch Gillet, Cristián, 2011: La buena fe contractual, Santiago: Editorial Jurídica de Chile.

Caballero Germaín, Guillermo, 2017: "La exclusión de un crédito del procedimiento concursal de una empresa deudora", Revista Chilena de Derecho Privado, No 29, pp. 347-361.

De la Maza Gazmuri, Íñigo, 2010a: "Tipicidad y atipicidad de los deberes precontractuales de información”, Revista de Derecho (Pontificia Universidad Católica de Valparaíso), XXXIV, pP. 75-99.

De la Maza Gazmuri, Íñigo, 2010b: Los límites del deber precontractual de información, Cizur Menor: Civitas Thomson Reuters.

Demogue, René, 1931: Traité des obligations en général. II. Effets des Obligations, Tomo VI, París: Librairie Arthur Rousseau.

Demolombe, C., 1868: Cours de Code Civil, Tomo XII, Bruselas : J. Stienon, Éditeur.

Díez-Picazo, Luis, 2008: Fundamentos del Derecho civil patrimonial, sexta edición, Cizur Menor: Thomson Civitas.

Fabre-Magnan, Muriel, 2014: De l'obligation d'information dans les contrats. Essai d'une théorie, París: LGDJ.

Fueyo Laneri, Fernando, 1958: Derecho civil. De Las Obligaciones. Tomo IV, Vol. I, Valparaíso / Santiago: Imp. y Lito. Universo S.A.

Fueyo Laneri, Fernando, 2004: Cumplimiento e incumplimiento de las obligaciones, tercera edición actualizada por el profesor Gonzalo Figueroa Yáñez, Santiago: Editorial Jurídica de Chile.

Goldenberg Serrano, Juan Luis, 2015: La visión privatista del Derecho concursal, Santiago: Thomson Reuters.

Goldenberg Serrano, Juan Luis, 2017: "La responsabilidad patrimonial universal y el sobreendeudamiento de la persona deudora”, en Hernán Corral y Pablo Manterola (editores), Estudios de Derecho Civil XII, Santiago: Thomson Reuters, pp. 239-255. 
Goldenberg Serrano, Juan Luis, 2018: "Los contornos del deber de consejo como expresión de la colaboración y como técnica de protección”, Revista de Derecho (Universidad de Concepción), $\mathrm{N}^{\circ} 244$, pp. 9-41.

GuZmÁn Brito, Alejandro, 2014: "El concepto de crédito en el Derecho chileno", Revista de Derecho (Universidad Católica del Norte), Año 21, Nº 2, pp. 439-452.

Hauriou, Maurice, 1910: Principes de Droit publique, París: Librairie de la Société du Recueil J.-B. Sirey \& du Journal de Palais.

Laurent, F., 1878: Principes de Droit français, Tomo XVI, tercera edición, Bruselas / París: Bruylant-Christophe \& Cie, Éditeurs / Librairie A, Marescq, Ainé.

Lestapis, Pierre de, 1941: La notion juridique de crédit. Etude de Droit civil français, París, Librairie Générale de Droit \& de Jurisprudence.

Levy, Jean-Philippe y Castaldo, André, 2002: Histoire du droit civil, París: Dalloz.

López Díaz, Patricia, 2017: "La tutela precontractual y contractual del acreedor en el Código Civil chileno: dos sistemas estructuralmente diversos, pero, ¿plenamente coherentes y convergentes?", Revista Chilena de Derecho Privado, N²9, pp. 9-98.

López Santa María, Jorge, 2010: Los contratos. Parte general, quinta edición actualizada por Fabián Elorriaga de Bonis, Santiago: Legal Publishing / Thomson Reuters.

Marcadé, V., 1850: Cours élémentaire de Droit Civil français, cuarta edición, Tomo IV, París: Librairie de Jurisprudence de Cotillon.

Migliaccio, Emanuela, 2012: La responsabilitá patrimoniale. Profili di sistema, Nápoles: Edizioni Scientifiche Italiane.

Morales Moreno, Antonio Manuel, 2011: “¿Es posible construir un sistema precontractual de remedios? Reflexiones sobre la propuesta de modernización del derecho de obligaciones y contratos en el marco del Derecho europeo”, en Klaus Jochen Albiez Dohrmann (dir.), Derecho privado europeo y modernización del Derecho contractual en España: Barcelona, Atelier, pp. 400-422.

Nicolò, Rosario, 1953: "Dei mezzi di conservazione della garanzia patrimoniale", en Comentario del Codice Civile a cura di Antonio Scialoja e Giuseppe Branca, Libro sesto, Tutela dei Diritti (art. 29002969), Bologna / Roma: Nicola Zanichelli Editore / Soc. Ed. Del Foro Italiano, pp. 1-271.

Paraiso, Fall, 2011: Le risque d'inexécution de l'obligation contractuelle, Aix-en-Provence: Presses Universitaires d'Aix-Marseille.

Palumbo, Filippo, 1935: L'actio pauliana nel Diritto romano e nel Diritto vigente, Nápoles: Alberto Morano Editore.

Puga Vial, Juan Esteban, 2014: Derecho concursal. Del procedimiento concursal de Liquidación, Santiago: Editorial Jurídica de Chile.

Ripert, Georges, 1936: Le régime démocratique et le Droit civil moderne, París: Librairie Générale de Droit et de Jurisprudence.

RIPERT, Georges, 1949: La règle morale dans les obligations civiles, quinta edición, París: Librairie Générale de Droit et de Jurisprudence.

Rojas Elgueta, Giacomo, 2012: Autonomia privata e responsabilitá patrimoniale del debitore, Milán: Giuffrè Editore.

Roman Rodríguez, Juan Pablo, 2011: Instituciones de Derecho concursal, Santiago: Abeledo Perrot / Thomson Reuters.

Sautonie-Lagouionie, Laura, 2008: La fraude paulienne, París: LGDJ.

Sandoval López, Ricardo, 2014: Reorganización y liquidación de empresas y personas. Derecho concursal, Santiago: Editorial Jurídica de Chile.

SAN MARTín NeIRA, Lilian, 2009: “Sobre la naturaleza jurídica de la 'cooperación' del acreedor el cumplimiento de la obligación: la posición dinámica del acreedor en la relación 
obligatoria, como sujeto no solo de derechos sino también de cargas y deberes", Revista de Derecho (Universidad de Concepción), N ${ }^{\text {os }}$ 225-226, pp. 135-196.

San Martín Neira, Lilian, 2012: "El deber de aviso ante la ocurrencia de un caso fortuito o fuerza mayor: ¿tiene aplicación en Chile?”, en Fabián Elorriaga (coordinador), Estudios de Derecho Civil VII, Santiago: Abeledo Perrot LegalPublishing, pp. 547-560.

SAVATIER, René, 1964: Les métamorphoses économiques et sociales du droit civil d'aujourd'bui, tercera edición, París: Dalloz.

Severin Fuster, Gonzalo y Carvajal Arenas, Lorena, 2016: "La acción pauliana civil en el procedimiento concursal. A propósito de la regulación de las acciones revocatorias en la Ley No 20.720", en Estudios de Derecho Civil XI. Jornadas Nacionales de Derecho Civil Concepción 2015, Santiago: Thomson Reuters La Ley, pp. 803-815.

Stolfi, Nicola, 1932: Diritto Civile, Vol. III. Le obbligazioni in generale, Turín: Unione TipográficoEditrice Torinense.

Touillier, C.M.B., 1821: Le droit civil français suivant l'ordre du Code, Tomo IV, Bruselas: Stapleaux, Imprimeur-Libraire du Roi et de S.A.R. le Prince d'Orange.

Troncoso Larronde, Hernán, 2011: De las obligaciones, séptima edición actualizada, Santiago: Legalpublishing / Thomson Reuters.

Vargas Vargas, Manuel, 1949: Tratado de la acción pauliana concursal, Vol. I, Santiago: Ediar Editores Limitada.

Warnotte, D., 1927: Les origines sociologiques de l'obligation contractuelle, Bruselas, Maurice Lamertin, Librairie-éditeur.

ZACHARIÆ, C.-S., 1842: Cours de Droit civil français, Tomo I, segunda edición revisada y aumentada por Aubry y Rau, Bruselas, Société Belge de Librairie.

Zuloaga Ríos, Isabel Margarita, 2006: Teoría de la responsabilidad precontractual, Santiago: LexisNexis.

Jurisprudencia citada

Corte Suprema, sentencia de 10 de septiembre de 1984, sin rol (pero, MJJ5425).

Corte de Apelaciones de Concepción, sentencia de 8 de octubre de 2010, rol 496-2010.

Corte Suprema, sentencia de 17 de agosto de 2011, rol 828-2010.

CORTE Suprema, sentencia de 23 de noviembre de 2012, rol 3397-2011.

CoRTe Suprema, sentencia de 23 de enero de 2014, rol 9010-2013.

Corte Suprema, sentencia de 7 de abril de 2014, rol 9432-2013.

Corte de Apelaciones de Santiago, sentencia de 2 de enero de 2015, rol 9392-2014.

Corte Suprema, sentencia de 31 de marzo de 2015, rol 30.917-2014.

CoRTe Suprema, sentencia de 28 de mayo de 2015, rol 24.381-2014.

CoRTe Suprema, sentencia de 30 de marzo de 2016, rol 9988-2015.

Corte Suprema, sentencia de 10 de noviembre de 2016, rol 17.517-2016.

Corte Suprema, sentencia de 24 de mayo de 2016, rol 22.750-2015.

Corte de Apelaciones de Concepción, sentencia de 31 de marzo de 2017, rol 1727-2016.

Corte Suprema, sentencia de 27 de septiembre de 2017, rol 30374-2017.

Corte Suprema, sentencia de 19 de octubre de 2017, rol 19.111-2017. 
